\title{
Mechanisms of cell competition emerging from Drosophila studies
}

\author{
Nicholas E. Baker \\ Department of Genetics, Department of Developmental and Molecular Biology, Department of \\ Ophthalmology and Visual Sciences, Albert Einstein College of Medicine, 1300 Morris Park \\ Avenue, Bronx, NY 10461
}

\begin{abstract}
Cell competition was described in Drosophila as the loss from mosaic tissues of otherwise viable cells heterozygous for Ribosomal protein mutations ('Minutes'). Cell competition has now been described to occur between multiple other genotypes, such as cells differing in myc expression levels, or mutated for neoplastic tumor suppressors. Recent studies implicate innate immunity components, and possibly mechanical stress, compression and cell intercalation as a consequence of differential growth rates in competitive cell death. Competition to eliminate pre-neoplastic tumors makes use of signals and receptors also used in patterning the nervous system including Slit/Robo2 and Sas/PTP10D to recognize and extrude clones of mutant cells, at least where local epithelial cyto-architecture is favorable. Cell competition facilitates expansion of Drosophila tumors through host tissue, and in normal development may promote developmental robustness and longevity by selecting for optimal progenitor cells.
\end{abstract}

\section{INTRODUCTION}

In 1975 Morata and Ripoll reported an interesting observation concerning a class of 'Minute' mutations that they were studying in Drosophila [1]. 'Minute' mutations dominantly slow cell growth and division rate. Almost all correspond to loss of function mutations of cytoplasmic ribosomal proteins [2,3]. Morata and Ripoll reported that although animals of these slow-growing genotypes were clearly viable, clones of cells of these genotypes generally could not survive in mosaics with wild type cells. They called this sensitivity of the Minute cells to a wild type cellular environment 'cell competition' [1] (Figure 1A).

It was soon suggested that mutations in other genes might also lead to cell competition [4]. Genotypes for which cell competition has now been specifically characterized are listed in Table 1. Some examples involve 'super-competitor' cells that out-compete normal, wild type cells. For example cells that express relatively more Myc are super-competitors [5,6](Figure 1B). In Drosophila, cell competition has only been observed in vivo in proliferating

Publisher's Disclaimer: This is a PDF file of an unedited manuscript that has been accepted for publication. As a service to our customers we are providing this early version of the manuscript. The manuscript will undergo copyediting, typesetting, and review of the resulting proof before it is published in its final citable form. Please note that during the production process errors may be discovered which could affect the content, and all legal disclaimers that apply to the journal pertain. 
epithelial tissues, such as the undifferentiated imaginal discs that comprise the precursor cells for adult structures, in the ovarian follicle, and in the adult gut $\left[1,7,8^{*}\right]$. Several examples of cell competition have now also been described in mammalian systems [9].

Many interesting questions about cell competition remain incompletely resolved. How are cells targeted for elimination only in mosaic environments? What is the adaptive significance of cell competition? Is cell competition conserved in mammals, and if so does it contribute to health or disease? There is particular interest in possible cell competition in cancer, because tumors generally differ genetically from surrounding cells and because many cell competition genes have mammalian homologs that are proto-oncogenes or tumor suppressors (Table 1). Cell competition has been comprehensively reviewed previously [10$13,9,14]$ and the present review serves to summarize recent developments in Drosophila, where there has been progress in understanding both apoptotic cell competition mechanisms and in mechanisms that involve cell extrusion from epithelia.

\section{Competitive apoptosis}

The competition of Minute cells by wild type cells relies on the induction of apoptosis. Minute cells survive in mosaic tissues when apoptosis is blocked $[15,16]$. Competition between cells that differ in myc expression level is similar. Myc mutant cells die in mosaics with wild type cells, and wild type cells undergo apoptosis in the presence of cells with higher $m y c$ gene copy numbers, or mildly elevated myc expression level [5,6]. Competitive apoptosis is concentrated near the interfaces between the genotypes, supporting earlier conclusions that competition is a local phenomenon $[17,5,18]$.

Is competitive apoptosis triggered by a molecular distinction that is recognized at the interface between the competing cells? Early reports focused on gene transcripts (or isoforms) that were up-regulated in cells under competition by Myc, which encoded Flower, Sparc and Azot proteins [19-21*]. If these expression changes reflect responses to a competitive situation, not apparent before cells with different Myc levels encounter one another, they may not represent the initial differences that first trigger the competition. More recently, it has been shown that components of innate immune pathways, including Tollrelated receptors and NF-KB transcription factors, are required during both Minute and Myc competition and stimulate cell death genes [22]. Although this is suggestive of altered-self recognition at competitive interfaces, no directional receptor-ligand interaction has yet been found. Perhaps molecular recognition of the competed cells occurs, but this is not the only possibility. It should particularly be noted that cells expressing more Myc are out-competing wild type, which could not ordinarily express a 'non-self' marker.

\section{Consequences of differential growth rates}

In many cases the out-competed cells are slower growing than their competitors. Also, cell competition occurs most efficiently in rapidly growing tissues where growth differences are accentuated. This raises the possibility that growth differences themselves are the direct cause of cell competition, not necessarily requiring any cell recognition event [17,23,24]. Hyperplastic clones result in local mechanical crowding, and increasing evidence points to 
crowding as a cause of cell delamination and death in epithelia [23,25,26]. Clones of cells expressing activated Ras ( $\mathrm{Ras}^{\mathrm{V} 12}$ ) are hyperplastic, compress the neighboring epithelium and eliminate cells lacking Ras ${ }^{\mathrm{V} 12}$ expression up to several cell diameters away [27*]. Faster growth does not seem sufficient to define a super-competitor cell, however, because hyperplastic cells do not always outcompete normal cells (for example hyperplastic cells activating the Insulin/IGF1 pathway, or over-expressing of CycD and Cdk4, are not supercompetitors) [5]. One possibility is that differences in the compression (or sensitivity to compression) among genotypes affect the outcome of differential growth.

The molecular pathway of cell death in response to crowding is not yet known in Drosophila. A form of mechanical competition that occurs between mammalian cells is mediated by p53. Certain out-competed mammalian genotypes, such as MDCK cells knocked-down for the apicobasal polarity gene scrib, elevate p53 expression, which renders them hyper-sensitive to their mechanical compaction in mixed epithelia [28**]. Drosophila p53 seems to lack this role, however, because Minute cells lacking p53 can be competed and killed by faster-growing wild type cells [16], and otherwise wild type cells lacking $p 53$ can be killed by hyperplastic supercompetitor cells expressing more Myc [29]. In Drosophila, on the other hand, p53 is required for cells over-expressing Myc to shift their metabolism towards glycolysis and super-compete wild type cells, and apparently protects the Myc overexpressing cells from DNA damage and death in the presence of wild type cells [29].

In Drosophila, compression due to differential growth activates the Salvador-Warts-Hippo (SWH) pathway of tumor suppressors that restrain the growth-promoting transcription factor Yorkie (Yki). This appears to confer homeostatic feedback that is thought to promote uniform growth in normal development [30*]. Reduction of Yki activity occurs in the core of faster growing cell populations, such as wild type clones in Minute discs [30*], however, which does not correspond to the location of competitive cell death, close to the clone boundaries. How cell competition may be linked to compression is also questioned by evidence that soluble factors generated in mixed tissue cultures lacking epithelial organization and associated mechanics can mediate competition [31,22].

\section{Intermingling of competing cells}

Cell competition appears to influence epithelial cell mixing. Boundaries between both wild type and Minute cells, and between cells expressing different myc levels, become more irregular with time as heterotypic interfaces are favored during cell rearrangements [17,32,33*]. Mixing between the populations is hypothesized to occur as a result of differential growth rates and enhance cell competition by increasing the area of competitive interactions [33*]. A possible mechanism is that competing cells may have different levels of PI3K activity, since PI3K activity affects epithelial cell rearrangements [34].

\section{Tumor-suppressive competition}

A further class of cell competition affects neoplastic tumor suppressors. These include genes that help define the polarity of epithelial cells ( $s c r i b, l g l, d l g$ ) as well as components of the endocytic system (vps25, erupted, Rab5 $5^{D N}$ )(Table 1). Mutants for these genes fail to 
recognize developmental growth arrest signals, leading to oversized imaginal discs that lose normal epithelial organization and grow as disorganized tumors [35]. By contrast to the whole animal mutants, clones of cells mutant for neoplastic tumor suppressors are eliminated from mosaics with wild type cells before they can become neoplastic. This 'tumor-suppressive competition' is partially independent of caspase-dependent apoptosis [36,37]. Although apoptosis does contribute, mutant cells are also removed by extrusion from mosaic epithelia, in both apical and basal directions [38**,39**].

Recent studies describe a web of cell interactions in tumor-suppressive competition(Figure 2). Extrusion of scrib mutant cells depends on Slit-Robo2 signaling through Enabled/Vasp (Ena), an actin nucleator that downregulates E-cadherin and also affects the actomyosin network [39**]. Slit-Robo2 signaling is not induced by wild type neighbor cells, but as a cell autonomous response to elevated Jnk signaling in all the scrib mutant cells [39**]. Jnk is activated by the TNF-alpha factor Eiger and its receptor Grindelwald, again cell autonomously, apparently as a consequence of altered endocytic activity in scrib cells $[37,40]$ (Figure 2).

Wild type cells are required for Slit-Robo2-Ena mediated extrusion indirectly [41**] (Figure 2). Wild type cells use Stranded at Second (Sas) to activate PTP10D, a receptor tyrosine phosphatase, in scrib cells at the clone borders. PTP10D signaling suppresses EGFR activity. Without PTP10D signaling, EGFR is also hyperactivated in scribclones and synergizes with Jnk signaling to inhibit SWH signaling and promote proliferation, survival, and tumorigenesis; it is only Jnk signaling by itself that promotes extrusion [41**].

Both PTP10D and Sas are apical transmembrane proteins that normally do not interact. Wild type cells abutting scrib clones relocalize Sas to basolateral membranes, and scrib cells abutting wildtpe cells relocalize PTP10D, so that trans signaling occurs only at the boundaries of scrib clones [41**](Figure 2). Defects in scrib cell polarity and endocytosis might account for basolateral PTP10D relocalization but how Sas is relocalized in wild type cells is uncertain. Interestingly, Egfr is also concentrated basolaterally at the boundaries of scrib clones [41**], suggesting a ligand is being presented basolaterally [42].

Another feature of the scrib clone boundary is that Eiger also activates JNK in the wild type cells adjacent to the clones [43]. This JNK activity promotes Pvr expression and activates Rac through ELMO to promote apoptotic engulfment of scrib mutant cells. This contributes to eliminating scrib mutant cells, although to a lesser extent than extrusion [43](Figure 2). How scrib cells activate TNF-alpha signaling to JNK in nearby wild type cells is unclear.

Although basal extrusion and apoptosis are tumor-suppressive, they are disfavored in certain tissue 'hotspots' defined by more robust basal matrix and microtubule networks. Here cells delaminate apically and can grow as neoplastic tumors by exploiting apical Jak-Stat signaling $\left[38^{* *}\right]$.

These studies provide an outline for how wild type cells interact with scrib mutant clones (and $d l g$, vps25, eru and Rab5 ${ }^{D N}$ clones) using Sas and PTP10D but many mechanistic questions are unanswered (Figure 2). Perhaps TNF signaling could be coupled to the apical determinant Crumbs, whose levels can also affect competition [44,40]. Although apoptosis 
contributes to tumor-suppressive competition [36,37,43], apoptotic cells are also sources of proliferative signals, which can be tumor sustaining under favorable conditions [45]. It has not been reported whether Drosophila cells lacking scrib activate p53, as in mammals [28**], or whether divergent mechanisms apply in Drosophila and mammals.

\section{Cell competition and cancer}

Many cell competition genes have mammalian homologs that are proto-oncogenes or tumor suppressors (Table 1). It is envisaged that cell competition could be exploited by tumors to overgrow wild type tissues (like super-competitors do: Figure 1B), in addition to tumorsuppressive competition (Figure 1A). Recent studies of Drosophila tumors have provided examples of super-competitor tumors.

As in mammals, clones of apc mutant cells in the Drosophila intestine grow as hyperplastic adenomas [ $46^{* *}$. The adenomas induce apoptosis of other nearby intestinal cells. Wild type clones near to adenomas show growth reduced by $75 \%$ and are often completely outcompeted. Blocking apoptosis restores normal growth to cells near the tumors and restricts adenoma expansion. In fact, it seems that hyperplasia of apc mutant clones is entirely dependent on killing neighboring cells to permit clonal expansion, so that the reaction of the surrounding normal tissue is determinative of tumor growth. Surrounding wild type cells were extremely sensitive to the SWH pathway, and even slight changes in SWH signaling that have no effect on normal intestines were sufficient to bolster wild type cells against competition and thereby prevent adenoma expansion [46**].

Another invasive tumor model results from overexpression of EGFR along with miR8. EGFR promotes hyperplasia while miR8 targets septin-7 to induce cytokinesis defects. The overgrowing EGFR+miR8 clones induce cell death in nearby wild type cells. However, EGFR+mir8 clones cannot expand through cells that have higher Myc levels, showing that these tumors are susceptible to suppression by competition, and might use competition themselves to expand through wild type cells [47].

\section{What is the function of cell competition?}

Why has cell competition evolved? Although the advantage of tumor-suppressive competition seems plain, Sas and PTP10D are not required for competition of Minute cells or by Myc supercompetitors, which may have evolved separately [ $\left.41^{* *}\right]$. Cell competition is able to buffer organ size in response to hyperplasia induced by elevated Myc levels by reducing the contribution of unaffected cells [5]. Some competition phenomena may occur as consequences of homeostatic responses to mechanical forces in epithelia; these would be important to maintain homogenous organ growth and to dissipate stress within epithelia [30*]. Mutations in azot, a putative calcium binding protein gene induced by Myc cell competition, are reported to shorten lifespan and accumulate developmental defects, illustrating the possibility that cell competition optimizes progenitor cell pools during development and aging by eliminating defective cells [21*]. Cell competition phenomena in mammals seem to fit this paradigm [9]. It is suggested in the DNA damage field that ribosomal protein genes, being predominantly single copy and distributed throughout the 
genome in Drosophila as in mammals, might be 'counted' as sentinels of aneuploidy and other major genome alterations, and that Minute cells are eliminated due to their resemblance to aneuploid cells $[48,49]$. Such a surveillance function for cell competition is one possible explanation for cancer predisposition in some ribosomopathies, although it would not explain why some human ribosomal protein genes are recurrently mutated in tumors themselves [50-52].

\section{CONCLUSIONS}

Recent progress begins to unravel the first steps in cell competition. It is notable that some pathways implicated are important in sculpting the nervous system (Slit/Robo2 and Sas/ PTP10D), and in immunity, two processes that also involve recognition at the cellular level [53-55]. Changes in protein localization and endosomal processing that accompany disruption of epithelial polarity appear to initiate tumor-suppressive competition. In future, a mechanism of molecular recognition related to innate immunity may be found to recognize competed genotypes such as Minutes and cells with less Myc. However, it will be important to assess the contribution of mechanical stresses due to differential growth, once the stresses can be mapped in vivo and the genes that respond to them identified and manipulated. At present distinct molecular pathways are being implicated in cell competition phenomena in Drosophila, although it may be too early to rule out connections between the mechanisms, especially as crosstalk can occur between between tumor suppressors, cell polarity pathways and innate immunity [56-58].

\section{Acknowledgments}

I thank Drs. E. Bach, A. Di Cristofano, T. Igaki, A. Jenny, M. Kiparaki, L. Johnston, A. Muesch and J. Secombe for comments on the manuscript. Research into cell competition in the author's laboratory is funded by grants from the NIH (GM104213, GM120451, EY026760).

\section{References}

* of particular interest

** of outstanding interest

1. Morata G, Ripoll P. Minutes: mutants of Drosophila autonomously affecting cell division rate. Developmental Biology. 1975; 42:211-221. [PubMed: 1116643]

2. Kongsuwan K, Yu Q, Vincent A, Frisardi MC, Rosbash M, Lengyel JA, Merriam J. A Drosophila Minute gene encodes a ribosomal protein. Nature. 1985; 317:555-558. [PubMed: 4047173]

3. Marygold SJ, Roote J, Reuter G, Lambertsson A, Ashburner M, Millburn GH, Harrison PM, Yu Z, Kenmochi N, Kaufman TC, et al. The ribosomal protein genes and Minute loci of Drosophila melanogaster. Genome Biol. 2007; 8:R216. [PubMed: 17927810]

4. Ripoll P. Behavior of somatic cells homozygous for zygotic lethals in Drosophila melanogaster. Genetics. 1977; 86:357-376. [PubMed: 407129]

5. de la Cova C, Abril M, Bellosta P, Gallant P, Johnston LA. Drosophila Myc regulates organ size by inducing cell competition. Cell. 2004; 117:107-116. [PubMed: 15066286]

6. Moreno E, Basler K. dMyc transforms cells into super-competitors. Cell. 2004; 117:117-129. [PubMed: 15066287]

7. Tamori Y, Deng WM. Tissue repair through cell competition and compensatory cellular hypertrophy in postmitotic epithelia. Dev Cell. 2013; 25:350-363. [PubMed: 23685249] 
*8. Kolahgar G, Suijkerbuijk SJ, Kucinski I, Poirier EZ, Mansour S, Simons BD, Piddini E. Cell Competition Modifies Adult Stem Cell and Tissue Population Dynamics in a JAK-STATDependent Manner. Dev Cell. 2015; 34:297-309. Cell competition of Minute cells is described in the posterior midgut, an adult epithelium that is a mix of stem, progenitor, and differentiated cell types. Competitive elimination of the Minute cells provides a selective advantage to the wild type cells, which also benefit from a Jak/Stat ligand secreted by Minute cells. [PubMed: 26212135]

9. Claveria C, Torres M. Cell Competition: Mechanisms and Physiological Roles. Annu Rev Cell Dev Biol. 2016; 32:411-439. [PubMed: 27501445]

10. de Beco S, Ziosi M, Johnston LA. New frontiers in cell competition. Dev Dyn. 2012; 241:831-841. [PubMed: 22438309]

11. Amoyel M, Bach EA. Cell competition: how to eliminate your neighbours. Development. 2014; 141:988-1000. [PubMed: 24550108]

12. Baillon L, Basler K. Reflections on cell competition. Semin Cell Dev Biol. 2014; 32:137-144. [PubMed: 24811317]

13. Gogna R, Shee K, Moreno E. Cell Competition During Growth and Regeneration. Annu Rev Genet. 2015; 49:697-718. [PubMed: 26631518]

14. Merino MM, Levayer R, Moreno E. Survival of the Fittest: Essential Roles of Cell Competition in Development, Aging, and Cancer. Trends Cell Biol. 2016; 26:776-788. [PubMed: 27319281]

15. Moreno E, Basler K, Morata G. Cells compete for decapentaplegic survival factor to prevent apoptosis in Drosophila wing development. Nature. 2002; 416:755-759. [PubMed: 11961558]

16. Kale A, Li W, Lee CH, Baker NE. Apoptotic mechanisms during competition of ribosomal protein mutant cells: roles of the initiator caspases Dronc and Dream/Strica. Cell Death Differ. 2015; 22:1300-1312. [PubMed: 25613379]

17. Simpson P, Morata G. Differential mitotic rates and patterns of growth in compartments in the Drosophila wing. Developmental Biology. 1981; 85:299-308. [PubMed: 7262460]

18. Li W, Baker NE. Engulfment is required for cell competition. Cell. 2007; 129:1215-1225. [PubMed: 17574031]

19. Portela M, Casas-Tinto S, Rhiner C, Lopez-Gay JM, Dominguez O, Soldini D, Moreno E. Drosophila SPARC is a self-protective signal expressed by loser cells during cell competition. Dev Cell. 2010; 19:562-573. [PubMed: 20951347]

20. Rhiner C, Lopez-Gay JM, Soldini D, Casas-Tinto S, Martin FA, Lombardia L, Moreno E. Flower forms an extracellular code that reveals the fitness of a cell to its neighbors in Drosophila. Dev Cell. 2010; 18:985-998. [PubMed: 20627080]

*21. Merino MM, Rhiner C, Lopez-Gay JM, Buechel D, Hauert B, Moreno E. Elimination of unfit cells maintains tissue health and prolongs lifespan. Cell. 2015; 160:461-476. The azot gene is identified as expressed during cell competition between cells differing in Myc expression levels and required to eliminate out-competed cells. Mutants for azot exhibit developmental defects and reduced longevity, whereas an extra genomic copy extends lifespan, suggesting that cell competition normally removes defective cells and promotes longevity. [PubMed: 25601460]

22. Meyer SN, Amoyel M, Bergantinos C, de la Cova C, Schertel C, Basler K, Johnston LA. An ancient defense system eliminates unfit cells from developing tissues during cell competition. Science. 2014; 346:1258236. [PubMed: 25477468]

23. Shraiman BI. Mechanical feedback as a possible regulator of tissue growth. Proc Natl Acad Sci U S A. 2005; 102:3318-3323. [PubMed: 15728365]

24. Vincent JP, Fletcher AG, Baena-Lopez LA. Mechanisms and mechanics of cell competition in epithelia. Nat Rev Mol Cell Biol. 2013; 14:581-591. [PubMed: 23942450]

25. Eisenhoffer GT, Loftus PD, Yoshigi M, Otsuna H, Chien CB, Morcos PA, Rosenblatt J. Crowding induces live cell extrusion to maintain homeostatic cell numbers in epithelia. Nature. 2012; 484:546-549. [PubMed: 22504183]

26. Marinari E, Mehonic A, Curran S, Gale J, Duke T, Baum B. Live-cell delamination counterbalances epithelial growth to limit tissue overcrowding. Nature. 2012; 484:542-545. [PubMed: 22504180]

*27. Levayer R, Dupont C, Moreno E. Tissue Crowding Induces Caspase-Dependent Competition for Space. Curr Biol. 2016; 26:670-677. Building on previous studies shows that epithelial crowding 
induces apoptosis as well as cell extrusion. Live imaging and Particle Image Velocimetry are used to quantify tissue deformation and infer patterns of compression associated with hyperplastic clones. The conclusion is that crowding-induced apoptosis may be a cell competition mechanism in epithelia with cells growing at different rates. [PubMed: 26898471]

**28. Wagstaff L, Goschorska M, Kozyrska K, Duclos G, Kucinski I, Chessel A, Hampton-O'Neil L, Bradshaw CR, Allen GE, Rawlins EL, et al. Mechanical cell competition kills cells via induction of lethal p53 levels. Nat Commun. 2016; 7:11373. A mechanical mechanism for competition between mammalian cells is described. Knock-down of the scrib gene renders MDCK cells hypersensitive to compaction, mediated by elevated p53 levels in scrib knockdown cells. Compaction further elevates p53 through a Rho-Associated Kinase and p38 pathway, achieving lethal p53 levels in compacted scrib knockdown cells. This can explain elimination of scrib knock-down cells mixed with faster-growing cells in epithelia. [PubMed: 27109213]

29. de la Cova C, Senoo-Matsuda N, Ziosi M, Wu DC, Bellosta P, Quinzii CM, Johnston LA. Supercompetitor status of Drosophila Myc cells requires p53 as a fitness sensor to reprogram metabolism and promote viability. Cell Metab. 2014; 19:470-483. [PubMed: 24561262]

*30. Pan Y, Heemskerk I, Ibar C, Shraiman BI, Irvine KD. Differential growth triggers mechanical feedback that elevates Hippo signaling. Proc Natl Acad Sci U S A. 2016 Reduced cell junctional tension within clones of faster growing imaginal disc cells modulates the SWH pathway. By decreasing recruitment of the Ajuba protein and Warts to cell junctions, reduced tension in faster growing cells de-represses Warts activity thereby inhibiting Yki-dependent growth. This acts as a homeostatic mechanism regulating normal growth as well as occurring in mosaics containing cells with different growth rates.

31. Senoo-Matsuda N, Johnston LA. Soluble factors mediate competitive and cooperative interactions between cells expressing different levels of Drosophila Myc. Proc Natl Acad Sci U S A. 2007; 104:18543-18548. [PubMed: 18000039]

32. Li W, Kale A, Baker NE. Oriented cell division as a response to cell death and cell competition. Curr Biol. 2009; 19:1821-1826. [PubMed: 19853449]

*33. Levayer R, Hauert B, Moreno E. Cell mixing induced by myc is required for competitive tissue invasion and destruction. Nature. 2015; 524:476-480. Live-imaging reveals that in epithelia mosaic for cells expressing more myc, or mosaic for wild type and Minute cells, interfaces between faster-growing cells have higher tension. This stabilizes interfaces between faster and slower growing cells during cell rearrangements, promoting intercalation between competing cell populations. Intercalation enhances cell competition as the faster-growing cells infiltrate the tissue, by increasing their exposure to the slower-growing population. [PubMed: 26287461]

34. Bardet PL, Guirao B, Paoletti C, Serman F, Leopold V, Bosveld F, Goya Y, Mirouse V, Graner F, Bellaiche Y. PTEN controls junction lengthening and stability during cell rearrangement in epithelial tissue. Dev Cell. 2013; 25:534-546. [PubMed: 23707736]

35. Hariharan IK, Bilder D. Regulation of imaginal disc growth by tumor-suppressor genes in Drosophila. Annu Rev Genet. 2006; 40:335-361. [PubMed: 16872256]

36. Brumby AM, Richardson HE. scribble mutants cooperate with oncogenic Ras or Notch to cause neoplastic overgrowth in Drosophila. Embo J. 2003; 22:5769-5779. [PubMed: 14592975]

37. Igaki T, Pastor-Pareja JC, Aonuma H, Miura M, Xu T. Intrinsic tumor suppression and epithelial maintenance by endocytic activation of Eiger/TNF signaling in Drosophila. Dev Cell. 2009; 16:458-465. [PubMed: 19289090]

**38. Tamori Y, Suzuki E, Deng WM. Epithelial Tumors Originate in Tumor Hotspots, a TissueIntrinsic Microenvironment. PLoS Biol. 2016; 14:e1002537. Robust cytoskeletal and matrix features that accompany epithelial folds provide a barrier to basal extrusion and apoptosis during tumor-suppressive competition, favoring apical extrusion instead. Cells extruded apically at such 'tumor hotspots' are prone to survival and tumorous growth, exploiting signaling molecules in the apical extracellular space. [PubMed: 27584724]

**39. Vaughen J, Igaki T. Slit-Robo Repulsive Signaling Extrudes Tumorigenic Cells from Epithelia. Dev Cell. 2016; 39:683-695. A genetic screen identifies Enabled/Vasp (Ena) as a gene required for tumor-suppressive competition. The activation of Ena by extracellular Slit and its receptor Robo 2 and by JnK signaling is described, and their contribution to extrusion of pre-neoplastic cells shown. [PubMed: 27997825] 
40. Andersen DS, Colombani J, Palmerini V, Chakrabandhu K, Boone E, Rothlisberger M, Toggweiler J, Basler K, Mapelli M, Hueber AO, et al. The Drosophila TNF receptor Grindelwald couples loss of cell polarity and neoplastic growth. Nature. 2015; 522:482-486. [PubMed: 25874673]

**41. Yamamoto M, Ohsawa S, Kunimasa K, Igaki T. The ligand Sas and its receptor PTP10D drive tumour-suppressive cell competition. Nature. 2017 A genetic screen identified Stranded at Second (Sas) as a gene required for tumor-suppressive competition. The local activation of PTP10D by Sas at the boundaries of clones mutant for scrib is described, and a mechanism by which PTP10D activity promotes extrusion of pre-neoplastic cells by down-regulating EGFR signaling is delineated.

42. Steinhauer J, Liu HH, Miller E, Treisman JE. Trafficking of the EGFR ligand Spitz regulates its signaling activity in polarized tissues. J Cell Sci. 2013; 126:4469-4478. [PubMed: 23902690]

43. Ohsawa S, Sugimura K, Takino K, Xu T, Miyawaki A, Igaki T. Elimination of oncogenic neighbors by JNK-mediated engulfment in Drosophila. Dev Cell. 2011; 20:315-328. [PubMed: 21397843]

44. Hafezi Y, Bosch JA, Hariharan IK. Differences in levels of the transmembrane protein Crumbs can influence cell survival at clonal boundaries. Dev Biol. 2012; 368:358-369. [PubMed: 22683826]

45. Ballesteros-Arias L, Saavedra V, Morata G. Cell competition may function either as tumoursuppressing or as tumour-stimulating factor in Drosophila. Oncogene. 2014; 33:4377-4384. [PubMed: 24096487]

**46. Suijkerbuijk SJ, Kolahgar G, Kucinski I, Piddini E. Cell Competition Drives the Growth of Intestinal Adenomas in Drosophila. Curr Biol. 2016; 26:428-438. Adenomas in the Drosophila intestine are studied as an example of tumor growth. These adenomas, which are mutated for apc, compete with and kill surrounding cells. This competitive loss of host cells is found to be required for adenoma expansion, so that tumor growth can be controlled if cell competition is prevented. [PubMed: 26853366]

47. Eichenlaub T, Cohen SM, Herranz H. Cell Competition Drives the Formation of Metastatic Tumors in a Drosophila Model of Epithelial Tumor Formation. Curr Biol. 2016; 26:419-427. [PubMed: 26853367]

48. Titen SW, Golic KG. Telomere loss provokes multiple pathways to apoptosis and produces genomic instability in Drosophila melanogaster. Genetics. 2008; 180:1821-1832. [PubMed: 18845846]

49. McNamee LM, Brodsky MH. p53-independent apoptosis limits DNA damage-induced aneuploidy. Genetics. 2009; 182:423-435. [PubMed: 19364807]

50. Vlachos A, Rosenberg PS, Atsidaftos E, Alter BP, Lipton JM. Incidence of neoplasia in Diamond Blackfan anemia: a report from the Diamond Blackfan Anemia Registry. Blood. 2012; 119:38153819. [PubMed: 22362038]

51. McCann KL, Baserga SJ. Genetics. Mysterious ribosomopathies. Science. 2013; 341:849-850. [PubMed: 23970686]

52. Baker NE, Kale A. Mutations in ribosomal proteins: Apoptosis, cell competition, and cancer. Mol Cell Oncol. 2016; 3:e1029065. [PubMed: 27308545]

53. Dickson BJ, Gilestro GF. Regulation of commissural axon pathfinding by slit and its Robo receptors. Annu Rev Cell Dev Biol. 2006; 22:651-675. [PubMed: 17029581]

54. Leulier F, Lemaitre B. Toll-like receptors--taking an evolutionary approach. Nat Rev Genet. 2008; 9:165-178. [PubMed: 18227810]

55. Lee HK, Cording A, Vielmetter J, Zinn K. Interactions between a receptor tyrosine phosphatase and a cell surface ligand regulate axon guidance and glial-neuronal communication. Neuron. 2013; 78:813-826. [PubMed: 23764287]

56. Forteza R, Wald FA, Mashukova A, Kozhekbaeva Z, Salas PJ. Par-complex aPKC and Par3 crosstalk with innate immunity NF-kappaB pathway in epithelial cells. Biol Open. 2013; 2:1264-1269. [PubMed: 24244864]

57. Guyer RA, Macara IG. Loss of the polarity protein PAR3 activates STAT3 signaling via an atypical protein kinase $\mathrm{C}(\mathrm{aPKC}) / \mathrm{NF}-\mathrm{kappaB} /$ interleukin-6 (IL-6) axis in mouse mammary cells. J Biol Chem. 2015; 290:8457-8468. [PubMed: 25657002]

58. Liu B, Zheng Y, Yin F, Yu J, Silverman N, Pan D. Toll Receptor-Mediated Hippo Signaling Controls Innate Immunity in Drosophila. Cell. 2016; 164:406-419. [PubMed: 26824654] 
59. Menendez J, Perez-Garijo A, Calleja M, Morata G. A tumor-suppressing mechanism in Drosophila involving cell competition and the Hippo pathway. Proc Natl Acad Sci U S A. 2010; 107:1465114656. [PubMed: 20679206]

60. Tamori Y, Bialucha CU, Tian AG, Kajita M, Huang YC, Norman M, Harrison N, Poulton J, Ivanovitch K, Disch L, et al. Involvement of Lgl and Mahjong/VprBP in cell competition. PLoS Biol. 2010; 8:e1000422. [PubMed: 20644714]

61. Thompson BJ, Mathieu J, Sung H-H, Loeser E, Rorth P, Cohen SM. Tumor Suppressor Properties of the ESCRT-II Complex Component Vps25 in Drosophila. Developmental Cell. 2005; 9:711720. [PubMed: 16256745]

62. Moberg KH, Schelble S, Burdick SK, Hariharan IK. Mutations in erupted, the Drosophila Ortholog of Mammalian Tumor Susceptibility Gene 101, Elicit Non-Cell-Autonomous Overgrowth. Developmental Cell. 2005; 9:699-710. [PubMed: 16256744]

63. Vincent JP, Kolahgar G, Gagliardi M, Piddini E. Steep differences in wingless signaling trigger Myc-independent competitive cell interactions. Dev Cell. 2011; 21:366-374. [PubMed: 21839923]

64. Fu W, Sun J, Huang G, Liu JC, Kaufman A, Ryan RJ, Ramanathan SY, Venkatesh T, Singh B. Squamous Cell Carcinoma-related Oncogene (SCCRO) Family Members Regulate Cell Growth and Proliferation through Their Cooperative and Antagonistic Effects on Cullin Neddylation. J Biol Chem. 2016; 291:6200-6217. [PubMed: 26792857]

65. Casas-Tinto S, Maraver A, Serrano M, Ferrus A. Troponin-I enhances and is required for oncogenic overgrowth. Oncotarget. 2016; 7:52631-52642. [PubMed: 27437768]

66. Tyler DM, Li W, Zhuo N, Pellock B, Baker NE. Genes affecting cell competition in Drosophila. Genetics. 2007; 175:643-657. [PubMed: 17110495]

67. Neto-Silva RM, de Beco S, Johnston LA. Evidence for a growth-stabilizing regulatory feedback mechanism between Myc and Yorkie, the Drosophila homolog of Yap. Dev Cell. 2010; 19:507520. [PubMed: 20951343]

68. Rodrigues AB, Zoranovic T, Ayala-Camargo A, Grewal S, Reyes-Robles T, Krasny M, Wu DC, Johnston LA, Bach EA. Activated STAT regulates growth and induces competitive interactions independently of Myc, Yorkie, Wingless and ribosome biogenesis. Development. 2012; 139:40514061. [PubMed: 22992954] 


\section{Highlights}

Instructions to authors states that Highlights are not required. 

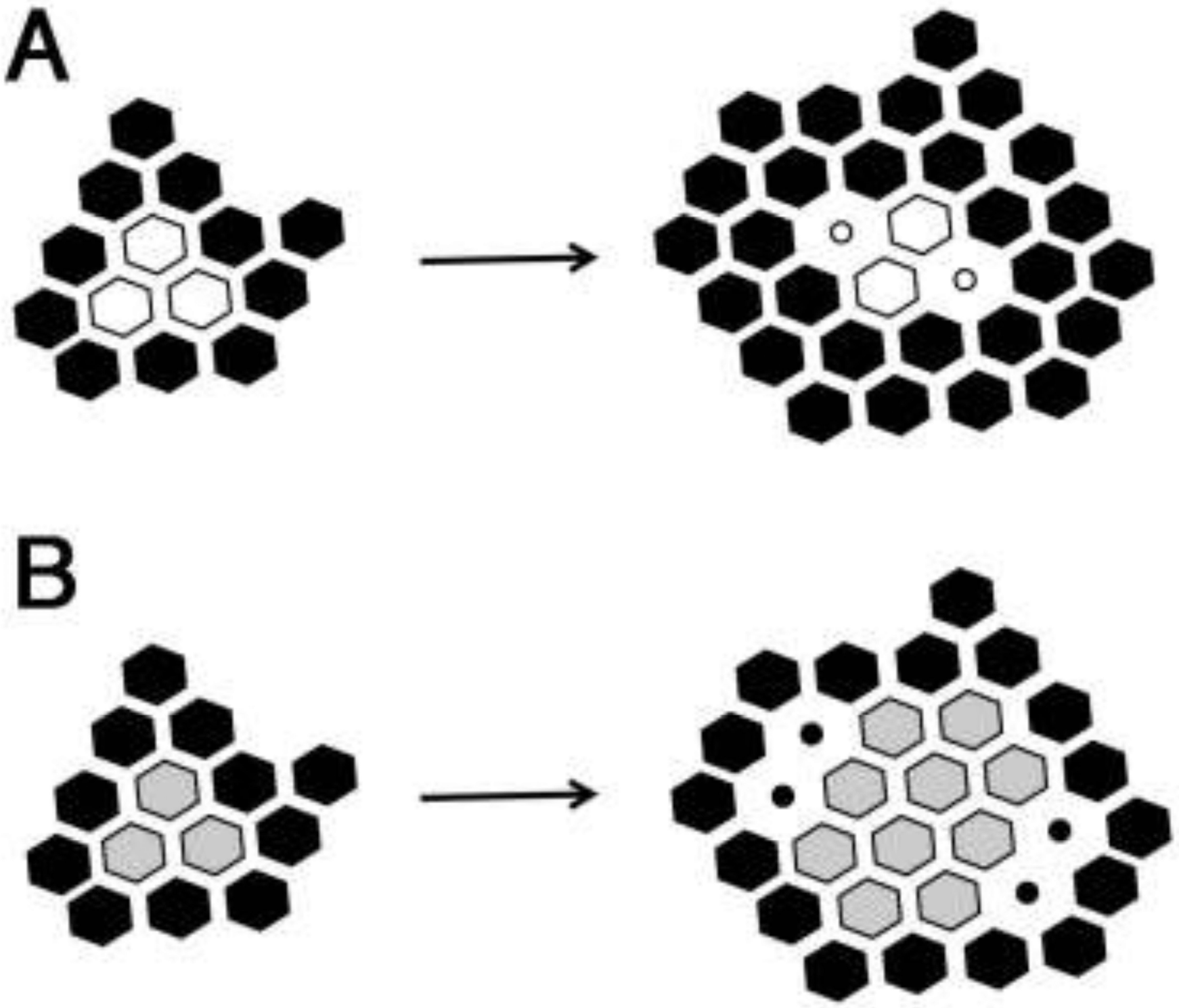

FIGURE 1. The phenomenon of cell competition

(A) In the classic example of cell competition shown by cells heterozygous for mutations of dose-sensitive Ribosomal protein genes ('Minute' cells), these slow-growing cells are actively eliminated from mosaic tissues containing wild type cells [1]. Clones of the 'Minute' cells (white) attempt to grow in the presence of normal cells (black), but apoptosis (small cells) progressively removes them $[15,16]$. Other examples of out-competed cells, including the neoplastic tumor mutants like scrib, are extruded from the epithelium as well as subject to cell death (see Figure 2) (B) In the converse situation, a clone of more competitive cells, for example cells expressing elevated Myc levels (grey), expand within the growing imaginal disc at the expense of surrounding normal cells (black), which are themselves killed (small cells) [5,22]. Not shown in panels (A) and (B) are the mechanical consequences of differential growth in epithelia. Typically, differential growth in mosaics 
leads to cell crowding and compaction in the vicinity of the faster-growing genotype $[23,30 *]$. 


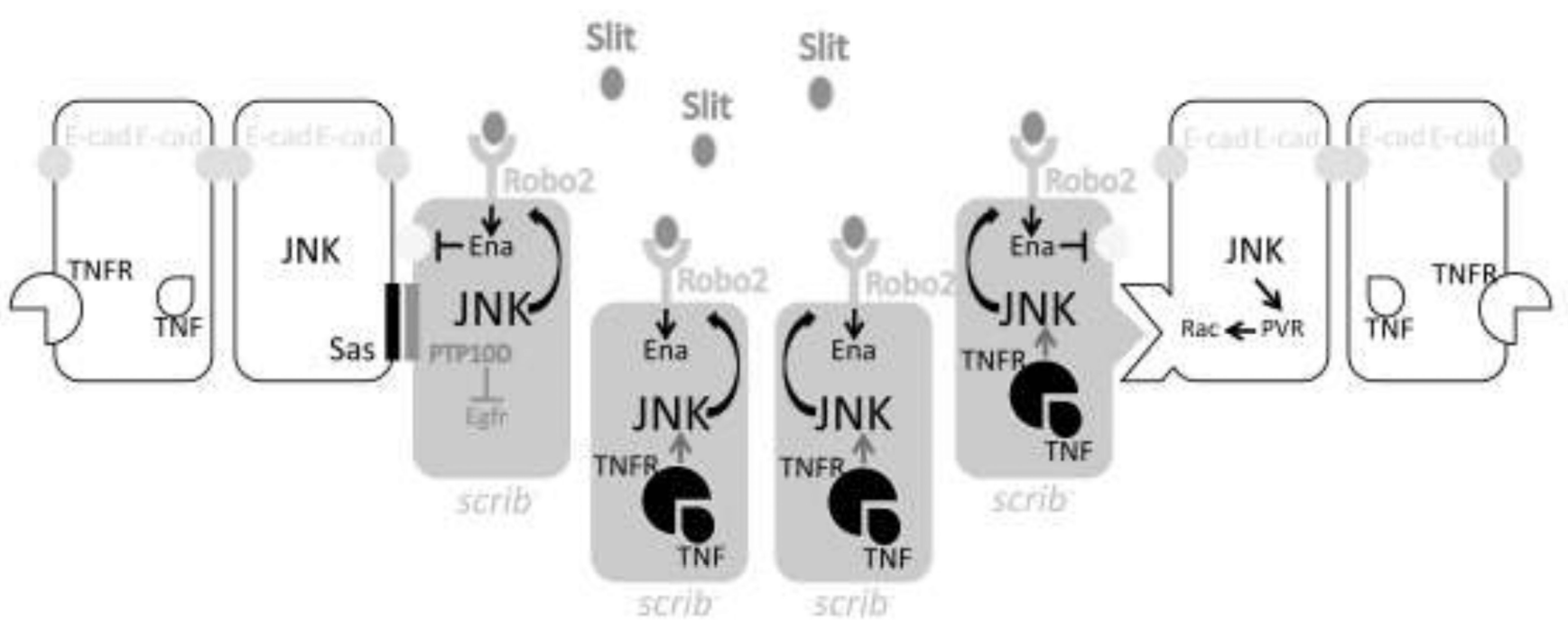

FIGURE 2. Tumor-suppressive competition

Clones of cells mutant for neoplastic tumor mutations, exemplified by scrib, are eliminated from mosaic imaginal discs by apoptosis and extrusion, depending on JNK signaling in the mutant cells. JNK is activated by the Drosophila TNF-alpha factor Eiger and its receptor Grindelwald as an autocrine consequence of disrupted polarity or endosomal function $[37,40]$. Within scrib mutant cells, JNK promotes autocrine activation of Slit/Robo2 signaling [39**]. Slit/Robo2 signaling through Ena downregulates E-cadherin and also affects the cytoskeleton to promote extrusion from the epithelium. This only occurs in mosaic tissues also containing wild type cells, because interaction between Sas in neighboring wild type cells and PTP10D in scrib mutant cells holds EGFR signaling to Ras in check. Without this suppression of EGFR signaling, combined Ras and JNK activity promote tumor growth and survival, not extrusion [41**]. Simultaneously, JNK activity in surrounding wild type cells promotes expression of the PDGF-receptor Pvr, which signals through ELMO and Rac to promote apoptosis and engulfment of the scrib mutant cells [43]. 


\section{TABLE 1}

Genotypes revealing cell competition in Drosophila imaginal discs

\begin{tabular}{|l|l|l|l|}
\hline genotype & $\begin{array}{l}\text { Outcompeted } \\
\text { by }\end{array}$ & reference & Human homolog \\
\hline Minute/+ (ie most Rp/+ genotypes) & Wild type & {$[1]$} & Rp \\
\hline scribble & Wild type & {$[36]$} & scribble \\
\hline Lethal giant larvae & Wild type & {$[59,60]$} & LLGL1,2 \\
\hline Discs large & Wild type & {$[37]$} & DLG1-4 \\
\hline Vps25 & Wild type & {$[61]$} & VPS25 \\
\hline Ept/TSG101 & Wild type & {$[62]$} & TSG101 \\
\hline Mahjong/VprBP/DCAF1 & Wild type & {$[60]$} & VprBP/DCAF1 \\
\hline Rab5 DN & Wild type & {$[45]$} & RAB5A,B,C \\
\hline Frizzled frizzled2 & Wild type & {$[63]$} & FZD1-10 \\
\hline $\begin{array}{l}\text { Squamous cell carcinoma-related oncogene ortholog } \\
\text { (Sccro) }\end{array}$ & Wild type & {$[64]$} & DCUN1D1,2 \\
\hline Troponin I (wupA) & Wild type & {$[65]$} & TNNI1,2,3 \\
\hline Wild type & Elevated myc & {$[5,6]$} & MYC \\
\hline Wild type & Ex,sav,wts, hpo, or mats & {$[66]$} & FRMD1?/SAV1/LATS1,2/STK3,4/MOB1A,B \\
\hline Wild type & Elevated Yki & {$[67]$} & YAP1 \\
\hline Wild type & Elevated Stat & {$[68]$} & STAT1-6 \\
\hline Wild type & Apc or axin & {$[63]$} & APC/APC2 or AXIN1,2 \\
\hline Wild type & Crumbs mutant & {$[44]$} & CRB1,2 \\
\hline
\end{tabular}

